\title{
STUDENT DISCUSSION FROM AN EVOLUTIONARY PERSPECTIVE
}

\author{
Matthew Metzgar ${ }^{7}$
}

\section{Introduction}

Student discussion has been identified as a key ingredient in overall student learning (Flynn \& Klein 2001; Safari et al 2006). However, in many classrooms, there is little to no discussion between teachers and students or among students themselves. This may result from high student-teacher ratios, or from the chosen pedagogy of the instructor.

A variety of ideas to increase class discussion have been proposed over time. A number of these ideas have been shown to increase student learning (Freeman et al 2014 for a recent meta-analysis). This paper attempts to analyze student discussion from a human evolutionary standpoint. Such a view may add new insights into how discussion can be effectively used in the classroom.

While looking at discussion from such an evolutionary view, several key questions arise: how and why did humans utilize discussion in the past? What are "natural conditions" for human discussion? How can these ideas help increase the use and effectiveness of discussion within an educational framework? This paper hopes to answer these questions and expound upon the evolutionary origins of productive discussion.

\section{The origins of discussion}

Discussion uses human language for communicating information. Though the origin of language is difficult to detect, it is estimated that humans have been using language for at least 100,000 years (Tattersall 2009). During this time, humans existed in small, nomadic hunter-gatherer bands, which date back for millions of years (Pritchard 2010). As such, discussion then would have taken place under these conditions of a small group, with mixed-age kin and non-kin adults and children (Hill et al 2011).

Discussion can be used for many purposes - social bonding, gossip, group decision-making, etc. The focus of discussion ofthis paper is, on its educational value, - i.e. how can discussion facilitate the understanding of intellectual ideas. The true value of intellectual discussion arises when there is debate - when differing viewpoints are presented and contested. In other words, if everyone agreemes on an issue, there is little need for group discussion. The potential value of discussion is the greatest when there are differing opinions.

Discussion within a group should also be more valued and necessary when there are shared outcomes. If a Person A wants some apples and a Person B wants some oranges, there is no need for discussion if they are acting independently. But if a Person

Matthew Metzgar- University of North Carolina at Charlotte, contact: <mmetzgar@uncc. 
A and a Person B must jointly decide on obtaining either apples or oranges, discussion and argumentation may be the natural consequence.

The idea that group decision-making prompts argumentation and discussion has been proposed as the "argumentative theory of reasoning" (Mercier \& Sperber 2011). The theory proposes that human reasoning developed as a tool to present and evaluate arguments within a group context. Recent research to support this theory includes evidence that argumentation is universal across cultures (Mercier 2011), and experimental evidence that young children are particularly sensitive to arguments (Bernard, Mercier, \& Clément 2012). Group reasoning has been found to be much more effective than individual reasoning across several domains (Trouche, Sander, \& Mercier 2014). Overall, this evidence suggests that argumentation within a group context may have evolutionary underpinnings.

The decision-making process of modern hunter-gatherer bands is related to this.. Existing hunter-gatherer bands have been found to be egalitarian in general, and democratic in their decision-making processes (Glassman 1986). The value of reasonable arguments would be very high under these circumstances, where logical persuasion, as opposed to force, would be the tool of choice. Furthermore, there is additional research on "collective rationality", with evidence showing that group members are sensitive to rational arguments (Moshman \& Geil 1998).

As mentioned above, discussion should be the most valuable when there are contrasting opinions. Given the presentation of differing arguments, it has been found that often "truth wins", meaning the most logical argument is likely to be accepted by the group (Laughlin \& Ellis 1986). Conversely, individual reasoning is often flawed and exhibits a confirmation bias (Jones \& Sugden 2001).

Overall, this research paints a picture of how and why discussion was potentially used throughout human history. Intellectual discussion was valuable or necessary when the matter was a group decision (where to move camp, if someone violated the rules, etc). Discussion and argumentation were the natural result when they were differing points of view within egalitarian, democratic, hunter-gatherer bands. Group reasoning can lead to more efficient outcomes as compared to individual reasoning due to the comparison of contrasting individual arguments.

\section{Educational Theory}

While the preceding discussion has been evolutionary based, there has been research within the educational field that has focused on similar themes. Educational research has developed several parallel lines of evidence showing the effectiveness of argumentation, collaborative learning, and democracy towards increasing student learning.

There is a large body of working showing that argumentation can increase the level of scientific thinking in students (Osbourne 2010). Dialogical argument has been shown to increase higher-order thinking skills (Kuhn \& Crowell 2011). Argumentation has also been shown to improve student engagement with the material (Nussbaum \& Sinatra 2003).

Collaborative learning has a long history in education at all levels (Bruffee 1984). A recent meta-analysis shows the overall effectiveness of collaborative learning (Kyndt et al 2013). Some forms of collaborative learning appear to have little effect, showing the importance of how these collaborative situations are structured (Prince 2004)

The use of democracy has also been shown to increase student engagement (Nagda, Gurin, \& Lopez 2003). Democratic practices have been shown to improve student learning and student attitudes in the classroom (Richter \& Tjosvold 1980). Democratic learning communities have also been shown to improve civic engagement (Finley 2011).

If these ideas from educational theory were synthesized with an evolutionary point 
of view, better models of student learning may be created. For example, collaborative learning "works" (i.e. increases understanding of the material) because it allows students to work together and reach a shared outcome, just as hunter-gatherer bands of the past had to do. Argumentation "works" (i.e. leads to a logical solution) because it allows students to present and evaluate different points of view, just as hunter-gatherer bands did and all cultures across the world still do. Democracy "works" (i.e. increases student engagement) because it replicates the egalitarian nature of hunter-gatherer groups, where each individual point of view carried equal weight.

Evolutionary theory gives these educational ideas a biological foundation, as opposed to context-free ideas that produce classroom success. By looking at these educational ideas from an evolutionary lens, they can potentially be refined and improved. Other research has already looked at the intersection of evolutionary thought and education for academic instruction and other student outcomes (Geary 2000).

\section{Educational Implications}

When looking at discussion from an evolutionary viewpoint, one can see the natural conditions that will encourage discussion to develop. These ideas can be applied to the classroom in order to maximize the potential of discussion in student learning.

In short, there are 5 main features derived from evolutionary theory that can generate productive student discussion:

1. The student outcomes must be shared.

If John thinks the answer is $A$, and Joan thinks the answer is $B$, the two students may or may not discuss their differences if they are being individually assessed. They may both exhibit the confirmation bias and believe that their individual answers are correct. However, if they must both agree on an answer, discussion and argumentation will be a natural product. In short, this means students should be in groups or in teams where they must submit one unified answer.

2. All students should have an equal say in a group's decision.

The effectiveness of group decision-making depends on the presentation of different arguments. In egalitarian and democratic situations, each person's view is equally valued. In any team or group, there must be mechanisms that allow the power to be dispersed among the group (i.e. one vote each) to prevent a forceful minority from silencing the arguments of others.

3. Groups should be heterogeneous.

If all members of a group are similar in their characteristics, culture, etc., there can be the possibility of "group think". Diversity of individual members within a group will bring about different points of view, and allow the group decision-making process to function more efficiently. A group of only like-minded individuals can bring about polarization (McCarty et al 1992; Sunstein 2002).

4. Group members must be accountable.

In a hunter-gatherer band, there was general continuity among its members, and hence there were incentives for social accountability to facilitate day-to-day living (Barceló et al 2014). In an educational setting, class groups will only last a short while and may meet infrequently. Therefore, care must be taken to make sure there is still some level of individual accountability in any group.

5. The issue or problem must be complex enough to merit discussion

A simple matter or problem that a person could solve on their own would not normally merit discussion. Complex situations that can be viewed in different ways would promote and usually benefit from discussion. Problems or situations that are ill-defined would also benefit more from discussion. 
These five principles, based upon evolutionary theory, can guide educational theory as to how best create the conditions that maximize the quality of student discussion. They are, in essence, a general framework that can predict how much discussion a teaching technique or environment will create.

These principles are similar to those described by Mercier et al (2017). The authors list a number of factors that should improve reasoning and discussion via evolutionary links. These are 1) Groups must exhibit trust and respect among the members 2) Groups must allow for lengthy arguments and free discussion, and 3) Group sizes should be kept small.

\section{Common Teaching Techniques}

It may be of interest then to look at some common teaching practices and analyze how much student discussion each technique generates. What follows is an analysis of four popular teaching techniques and predictions as to how much student discussion they will generate.

1. Call-and-response during a lecture

Instructors often call on students during a lecture to answer questions or solve problems. This technique will likely generate only minimal discussion. A student is generally answering alone and has no shared outcome from which to contribute. Typically all or most of the course grade is individual. None of the principles for generating student discussion are met.

\section{Informal group work}

Techniques such as think-pair-share or informal groups may facilitate some student discussion. However, groups/pairs are generally temporary, lessening the need to be accountable. Though there may be a shared outcome (present a joint answer), it is not clear if this outcome has any individual consequences. There is also no guarantee that random groups, or especially pairs, would be heterogeneous.

\section{Peer Instruction}

Peer Instruction was developed by Eric Mazur as a way to facilitate physics understanding (Mazur 1997). The technique involves student discussion revolving around "clicker" questions presented in class. This technique greatly increases student discussion as compared to a lecture class and has been shown to increase student learning (Crouch \& Mazur 2001).

While this technique may generate student discussion, the lack of shared outcomes may lessen motivation. If students are being individual graded on clicker questions and exams, instructors may have to prod some students into discussion. Students may sit next to friends in class, lessening the likelihood that there are diverse points of view in the student discussion.

\section{Team-based Learning}

This technique should generate a large amount of quality student discussion, depending on how it is structured. Teams can be created in such a way that they are heterogeneous. Team grading will create a shared outcome. Individuals can be held accountable through peer reviews, and perhaps through permanent teams. Potential continuity problems may arise with members who "drop out" or in situation where a group wants to "fire" a member.

\section{Conclusion}

Discussion appears to have played a key role in human evolution. A historic analysis shows the conditions that led to argumentation and discussion within hunter-gatherer bands. The presence of shared group outcomes led to argumentation and debate 
within these groups. The egalitarian and democratic nature of the bands created conditions that favored logical arguments.

Along parallel lines, the education literature has shown the value of collaborative learning, argumentation, and democracy as ways to increase student learning. A large body of empirical evidence supports these techniques as being effective. By nesting these ideas in an evolutionary framework, the advantages and disadvantages become clearer.

By duplicating the evolutionary conditions that naturally favor discussion, instructors may be able to maximize the amount and quality of student discussion. Predictions can also be made as to level of discussion a teaching technique may generate. Teaching techniques that focus on individual assessment and individual grading will likely generate little discussion. Techniques that are group or team-based with shared grading are likely to generate a greater quantity and quality of student discussion. Replicating the conditions of group decision-making from our evolutionary past may increase student learning and engagement in the classroom.

In conclusion, human discussion evolved for specific purposes in our evolutionary past. Creating conditions similar to this past environment may generate improved discussion and reasoning. By applying these conditions within an educational framework, instructors may be able to create high-quality discussion and improved student outcomes.

\section{References}

BARCELÓ, J. A., BERNAL, F. D. C., DEL OLMO, R., MAMELI, L., QUESADA, F. M., POZA, D., \& VILÀ, X. (2014). Social Interaction in Hunter-Gatherer Societies Simulating the Consequences of Cooperation and Social Aggregation. Social Science Computer Review, 32(3), 417-436.

BERNARD, S., MERCIER, H., \& CLÉMENT, F. (2012). The power of well-connected arguments: Early sensitivity to the connective because. Journal of experimental child psychology, 111(1), 128-135.

BRUFFEE, K. A. (1984). Collaborative learning and the" conversation of mankind". College English, 635-652.

CROUCH, C. H., \& MAZUR, E. (2001). Peer instruction: Ten years of experience and results. American Journal of Physics, 69(9), 970-977.

FINLEY, A. (2011). Civic learning and democratic engagements: A review of the literature on civic engagement in post-secondary education. Unpublished paper. Accessed October, 12, 2014.

FLYNN, A. E., \& KLEIN, J. D. (2001). The influence of discussion groups in a case-based learning environment. Educational Technology Research and Development, 49(3), 71-86.

FREEMAN, S., EDDY, S. L., MCDONOUGH, M., SMITH, M. K., OKOROAFOR, N., JORDT, H., \& WENDEROTH, M. P. (2014). Active learning increases student performance in science, engineering, and mathematics. Proceedings of the National Academy of Sciences, 201319030.

GEARY, D. C. (2000). Principles of evolutionary educational psychology. Learning and individual differences, 12(4), 317-345.

GLASSMAN, R. M. (1986). Democracy and despotism in primitive societies: A neo-Weberian approach to political theory. Port Washington, N.Y: Associated Faculty Press.

HILL, K. R., WALKER, R. S., BOŽIČEVIĆ, M., EDER, J., HEADLAND, T., HEWLETT, B., ... \& WOOD, B. (2011). Co-residence patterns in hunter-gatherer societies show unique human social structure. Science, 331(6022), 1286-1289.

JONES, M., \& SUGDEN, R. (2001). Positive confirmation bias in the acquisition of information. Theory and Decision, 50(1), 59-99.

KUHN, D., \& CROWELL, A. (2011). Dialogic argumentation as a vehicle for developing young adolescents' thinking. Psychological Science, 22(4), 545-552.

KYNDT, E., RAES, E., LISMONT, B., TIMMERS, F., CASCALLAR, E., \& DOCHY, F. (2013). A meta-analysis of the effects of face-to-face cooperative learning. Do recent studies falsify or verify earlier findings?. Educational Research Review, 10, 133-149. 
LAUGHLIN, P. R., \& ELLIS, A. L. (1986). Demonstrability and social combination processes on mathematical intellective tasks. Journal of Experimental Social Psychology, 22(3), 177-189.

MAZUR, E. (1997). Peer instruction (pp. 9-18). Upper Saddle River, NJ: Prentice Hall.

MCGARTY, C., TURNER, J. C., HOGG, M. A., DAVID, B., \& WETHERELL, M. S. (1992). Group polarization as conformity to the prototypical group member. British Journal of Social Psychology, 31(1), 1-19.

MERCIER, H. (2011). On the universality of argumentative reasoning. Journal of Cognition and Culture, 11(1-2), 1-2.

MERCIER, H., \& SPERBER, D. (2011). Why do humans reason? Arguments for an argumentative theory. Behavioral and brain sciences, 34(02), 57-74.

MERCIER, H., BOUDRY, M., PAGLIERI, F., \& TROUCHE, E. (2017). Natural-born arguers: Teaching how to make the best of our reasoning abilities. Educational Psychologist, 52(1), 1-16.

MOSHMAN, D., \& GEIL, M. (1998). Collaborative reasoning: Evidence for collective rationality. Thinking \& Reasoning, 4(3), 231-248.

NAGDA, B. R. A., GURIN, P., \& LOPEZ, G. E. (2003). Transformative pedagogy for democracy and social justice. Race, ethnicity and education, 6(2), 165-191.

NUSSBAUM, E. M., \& SINATRA, G. M. (2003). Argument and conceptual engagement. Contemporary Educational Psychology, 28(3), 384-395.

OSBORNE, J. (2010). Arguing to learn in science: The role of collaborative, critical discourse. Science, 328(5977), 463-466.

PRINCE, M. (2004). Does active learning work? A review of the research. Journal of engineering education, 93(3), 223-231.

PRITCHARD, J. K. (2010). How we are evolving. Scientific American, 303(4), 40-47.

RICHTER, F. D., \& TJOSVOLD, D. (1980). Effects of student participation in classroom decision making on attitudes, peer interaction, motivation, and learning. Journal of Applied Psychology, 65(1), 74.

SAFARI, M., YAZDANPANAH, B., GHAFARIAN, H. R., \& YAZDANPANAH, S. (2006). Comparing the effect of lecture and discussion methods on students learning and satisfaction. Iranian journal of medical education, 6(1), 59-64.

SUNSTEIN, C. R. (2002). The law of group polarization. Journal of political philosophy, 10(2), 175-195.

TATTERSALL, I. (2009). "Language and the origin of symbolic thought," in Cognitive Archaeology and Human Evolution, eds S. A. De Beaune, F. L. Coolidge, and T. G. Wynn (New York, NY: Cambridge University Press), 109-116.

TROUCHE, E., SANDER, E., \& MERCIER, H. (2014). Arguments, More than Confidence, Explain the Good Performance of Reasoning Groups. Journal of Experimental Psychology: General (Forthcoming). 